OPEN ACCESS

Edited by:

Amit Kumar Tyagi,

The University of Texas MD Anderson

Cancer Center, USA

Reviewed by:

Soner Soylu,

Mustafa Kemal University, Turkey

Shinjini Singh,

The University of Texas MD Anderson

Cancer Center, USA

${ }^{*}$ Correspondence:

Shiping Tian

tsp@ibcas.ac.cn

Specialty section:

This article was submitted to

Food Microbiology,

a section of the journal

Frontiers in Microbiology

Received: 29 January 2016

Accepted: 11 April 2016

Published: 03 May 2016

Citation:

LiB, Peng H and Tian S (2016) Attachment Capability of Antagonistic Yeast Rhodotorula glutinis to Botrytis cinerea Contributes to Biocontrol Efficacy. Front. Microbiol. 7:601. doi: 10.3389/fmicb.2016.00601

\section{Attachment Capability of Antagonistic Yeast Rhodotorula glutinis to Botrytis cinerea Contributes to Biocontrol Efficacy}

\author{
Boqiang $\mathrm{Li}^{1}$, Huaimin Peng ${ }^{1,2}$ and Shiping Tian ${ }^{1 *}$ \\ ${ }^{1}$ Key Laboratory of Plant Resources, Institute of Botany, Chinese Academy of Sciences, Beijing, China, ${ }^{2}$ University of \\ Chinese Academy of Sciences, Beijing, China
}

Rhodotorula glutinis as an antagonism show good biocontrol performance against various post-harvest diseases in fruits. In the present study, strong attachment capability of $R$. glutinis to spores and hyphae of Botrytis cinerea was observed. Further analysis showed that certain protein components on the yeast cell surface played critical role during the interaction between $R$. glutinis and $B$. cinerea. The components mainly distributed at the poles of yeast cells and might contain glycosylation modification, as tunicamycin treated yeast cells lost attachment capability to $B$. cinerea. To investigate contributions of attachment capability of $R$. glutinis to its biocontrol efficacy, yeast cells were mutagenized with $3 \%$ methane-sulfonic acid ethyl ester (EMS), and a mutant CE4 with stable non-attaching phenotype was obtained. No significant difference was found on colony, cell morphology, reproductive ability, and capsule formation between the mutant and wild-type. However, there was a distinct difference in India ink positive staining patterns between the two strains. Moreover, wild-type strain of $R$. glutinis showed better performance on inhibiting spore germination and mycelial growth of $B$. cinerea than CE4 strain when yeast cells and B. cinerea were co-cultured in vitro. In biocontrol assay, both wild-type and CE4 strains showed significant biocontrol efficacy against gray mold caused by $B$. cinerea in apple fruit, whereas, control effect of CE4 strain was lower than that of wild-type. Our findings provided new evidences that attachment capability of $R$. glutinis to $B$. cinerea contributed to its biocontrol efficacy.

Keywords: attachment, biological control, EMS mutagenization, gray mold, yeast

\section{INTRODUCTION}

Post-harvest decay of fruits and vegetables results in major economic losses. By far, the use of synthetic fungicide remains the main method for controlling post-harvest diseases (Droby et al., 2009). However, due to increasing public concern on environmental pollution and food safety causing by fungicide residues, some new strategies were developed as alternatives to manage postharvest decay. Among them, biological control using microbial antagonists was considered as one of the most promising ways (Spadaro and Gullino, 2004; Liu et al., 2013).

In comparison with other microbial antagonists, yeasts have a number of attributes which make them suitable as biocontrol agents for post-harvest disease control, such as simple nutritional 
requirements, survival in adverse environmental conditions, good performances against a wide range of pathogens on different commodities, and compatibility with commercial processing procedures (Droby et al., 2009). Many yeast species have been reported to be effective biocontrol agents against postharvest diseases (Wisniewski et al., 2007; Sharma et al., 2009; Liu et al., 2013). Action modes of antagonistic yeasts include competition for space, nutrition and iron, formation of biofilm, production of antifungal diffusible and volatile metabolites, induction of host resistance, and mycoparasitism (Spadaro and Droby, 2016). Among them, mycoparasitism is interesting, in which antagonistic yeasts show capability of attaching tenaciously to fungal pathogens. Allen et al. (2004) tested attachment capability of 294 phylloplane yeast isolates to spores of Botrytis cinerea and found that 260 isolates showed positive attachment. Among these isolates, several yeast species were reported as biocontrol agents, such as Cryptococcus laurentii, Pichia guilliermondii, and Rhodotorula glutinis, and showed good performance against various post-harvest pathogens (Yu et al., 2007, 2013; Zhang et al., 2010, 2011; Lahlali et al., 2014; Yan et al., 2014). With attachment, antagonistic yeasts could cause pitting and collapse on the surface of pathogen mycelium, and severe internal injury, such as protoplasm degeneration (Wisniewski et al., 1991; El-Ghaouth et al., 1998). Mycelial degradation may be associated with the secretion of chitinase, glucanase, and protease from antagonistic yeasts (Chan and Tian, 2005; Zhang et al., 2011; Banani et al., 2014). In addition, the attachment capability of antagonistic yeasts may play a key role by either enhancing nutrient competition or some other undetermined mechanism (Wisniewski et al., 1991). Although attachment of antagonistic yeasts to fungal pathogens is considered as contributing to the biocontrol efficacy, few data by far has indicated that how important the attachment capability is.

Botrytis cinerea, a necrotrophic fungal pathogen, causes gray mold disease in more than 200 host plant species and is especially destructive on fruits and vegetables (Williamson et al., 2007). The pathogen is capable of transferring sRNA effectors into host plant cells to suppress host immunity and secreting a large set of enzymes to kill host cells during the infection process ( $\mathrm{Li}$ et al., 2012; Weiberg et al., 2013). Fungicide-resistant strains of $B$. cinerea frequently emerge in field, and alternatives are needed to effectively control the pathogen. It has been reported that essential oils obtained from aromatic plants could markedly inhibit spore germination and mycelial growth of $B$. cinerea in vitro, and showed good protection against gray mold disease in tomato under greenhouse condition (Soylu et al., 2010). Besides essential oils, biological control is also considered as a promising way for control of $B$. cinerea. As an antagonistic agent, $R$. glutinis has presented good biocontrol efficacy against gray mold in different fruits (Zhang et al., 2009; Ge et al., 2010) and other post-harvest diseases caused by Penicillium expansum (Chen et al., 2015), Alternaria alternata (Yan et al., 2014), Rhizopus stolonifer (Zhang et al., 2010). In our preliminary study, a strain of $R$. glutinis isolated in our previous study (Qin et al., 2003) was found to exhibit strong attachment capability to spores and hyphae of $B$. cinerea.
In order to investigate the role of attachment of the yeast strain in biocontrol efficacy, we generated a non-attaching mutant by EMS mutagenesis, and compared biological characteristics and biocontrol efficacy between non-attaching mutant and wild-type.

\section{MATERIALS AND METHODS}

\section{Yeast Strain}

Rhodotorula glutinis (Fresen.) F.C. Harrison was isolated in the previous experiment and identified by CABI Bioscience (Egham, UK) (Qin et al., 2003). The strain was preserved in glycerol at $-80^{\circ} \mathrm{C}$. Before the experiment, it was inoculated and maintained in yeast peptone dextrose (YPD) medium at $26^{\circ} \mathrm{C}$.

\section{Pathogen}

Botrytis cinerea B05.10 was kindly provided by Dr. Tudzynski (Westfälische Wilhelms-Universität Münster, Germany). The pathogen was maintained on potato dextrose agar (PDA) at $4^{\circ} \mathrm{C}$. For the production of $R$. glutinis non-attaching mutants, mycelia were collected after $B$. cinerea was cultured for 2 weeks at $22^{\circ} \mathrm{C}$ on PDA. For attachment and biocontrol assays, spores were collected and resuspended with sterile distilled water.

\section{Fruit}

'Fuji' apples (Malus domestica Borkh.) with commercial maturity and without wounds or rot were classified according to their uniformity of size. Then, the selected fruit were surfacedisinfected with $2 \%(\mathrm{v} / \mathrm{v})$ sodium hypochlorite for $2 \mathrm{~min}$, washed with tap water and air-dried prior to use (Yao et al., 2004).

\section{Attachment Assay between R. glutinis and $B$. cinerea}

The yeast cells cultured in YPD medium were collected at late log-phase, resuspended to $2 \times 10^{8}$ cells $/ \mathrm{mL}$ after washing three times using sterile distilled water. Then, aliquot of yeast cell suspension was mixed with equal volume of $B$. cinerea spore suspension at the concentration of $1 \times 10^{7}$ spores $/ \mathrm{mL}$. After vortex for $30 \mathrm{~s}$, aliquot of $20 \mu \mathrm{L}$ of the mixture was loaded onto a haemocytometer, and observed under Zeiss Axioskop 40 microscope (Carl Zeiss, Oberkochen, Germany). To facilitate the observation on the budding sites of yeast cells, fluorescent dye calcofluor white (Sigma, Saint Louis, MO, USA) was used at the concentration of $100 \mu \mathrm{g} / \mathrm{mL}$.

\section{Scanning Electron Microscopy (SEM) Observation}

The yeast cells cultured in YPD medium were collected at late logphase, resuspended to $2 \times 10^{8}$ cells $/ \mathrm{mL}$ after washing three times using 0.1 M PBS (pH7.4). Then, aliquot of yeast cell suspension was mixed with equal volume of $B$. cinerea spore suspension at the concentration of $1 \times 10^{7}$ spores $/ \mathrm{mL}$. After vortex for $30 \mathrm{~s}$, the mixture was centrifuged ( $300 \mathrm{~g}, 15 \mathrm{~s}$ ), the supernate containing un-attached yeast cells was removed. The pellet was gently resuspended and fixed with $100 \mu \mathrm{L}$ glutaraldehyde solution $(2.5 \%)$ for $2 \mathrm{~h}$ at $25^{\circ} \mathrm{C}$. After centrifugation (300 g, $15 \mathrm{~s}$ ) and 
washing twice with $\mathrm{dd} \mathrm{H}_{2} \mathrm{O}$, post-fixation was performed with $1 \%$ osmium acid for $1 \mathrm{~h}$ at $25^{\circ} \mathrm{C}$. The fixed sample was washed three times with $\mathrm{dd} \mathrm{H}_{2} \mathrm{O}$, and completely dried in a vacuum centrifuge. Then, the sample was coated with gold-palladium and observed under Hitachi S-4800 SEM (Japan).

\section{Effects of Cell Surface Extract of R. glutinis on Attachment between Yeast Cells and Spores of $B$. cinerea}

The yeast cells cultured in YPD medium for 48 h were collected, resuspended to $1 \times 10^{9}$ cells $/ \mathrm{mL}$ after washing three times using sterile distilled water. Aliquots of $1 \mathrm{~mL}$ yeast cell suspension were added into 1.5-mL EP tubes, and vibrated using cell disruptor (Disruptor Genie, Scientific Industries, New York, NY, USA) for $20 \mathrm{~min}$ ( $2 \mathrm{~min}$ each time with interval of $2 \mathrm{~min}$ in ice bath, a total of 10 times). After centrifugation $(10,000 \mathrm{~g}, 5 \mathrm{~min})$, the supernate was collected as cell surface extract (CSE). The spores of $B$. cinerea were suspended with CSE at concentration of $1 \times 10^{7}$ spores $/ \mathrm{mL}$. After incubated for $30 \mathrm{~min}$ at $25^{\circ} \mathrm{C}$, spores were mixed with equal volume of $2 \times 10^{8}$ cells $/ \mathrm{mL}$ yeast cell suspension. The attachment between yeast cells and spores of $B$. cinerea was examined under microscope. To determine the role of proteins in CSE on inhibiting attachment between yeast cells and spores of B. cinerea, CSE was digested with Pronase E (Sigma, Saint Louis, $\mathrm{MO}, \mathrm{USA}$ ) at final concentration of $2 \mathrm{mg} / \mathrm{mL}$ for $1 \mathrm{~h}$ prior to attachment assay.

\section{Tunicamycin Treatment and FITC-ConA Fluorescence Staining}

The yeast cells were collected after cultured for $48 \mathrm{~h}$ in YPD medium with or without $5 \mu \mathrm{g} / \mathrm{mL}$ tunicamycin (Sigma, Saint Louis, MO, USA). The collected cells were washed with lectin buffer (10 mM HEPES [pH 7.5], $0.15 \mathrm{M} \mathrm{NaCl}, 0.1 \mathrm{mM} \mathrm{CaCl}$, $\left.0.01 \mathrm{mM} \mathrm{MnCl}_{2}\right)$, and incubated with FITC-Con A $(100 \mu \mathrm{g} / \mathrm{mL})$ (Sigma, Saint Louis, MO, USA) for $30 \mathrm{~min}$ at $25^{\circ} \mathrm{C}$. After washing twice with lectin buffer, yeast cells were examined under a Zeiss Axioskop 40 microscope equipped with a UV-light source using a 485-nm excitation and 530-nm emission filter combination. The attachment assay of yeast cells treated with or without tunicamycin was performed as described above.

\section{Production of R. glutinis Non-attaching Mutants}

Rhodotorula glutinis non-attaching mutants were obtained according to the method of Buck and Andrews (1999a) with some modifications. Briefly, yeast cells were collected at late logphase, and mutagenized with 3\% methane-sulfonic acid ethyl ester (EMS) for $40 \mathrm{~min}$, which killed approximately $50 \%$ of the initial population. Following mutagenesis, the cells were divided into three fractions (Fraction A, B, and C). Each fraction representing a separate mutagenized population was cultured in YPD. After $24 \mathrm{~h}$, each culture containing mutagenized cells was collected into centrifuge tube by centrifugation $(3,000 \mathrm{~g}$, $5 \mathrm{~min}$ ), washed and resuspended with sterile distilled water. Then, mycelia of $B$. cinerea were added to each tube, and the mixture was vortexed for $1 \mathrm{~min}$. With centrifugation (500 g,
$30 \mathrm{~s}$ ), pathogen mycelia with attached yeast cells were pelleted, and non-attaching yeast cells in the supernate were transferred. The procedure was repeated for at least 4 times to enrich nonattaching cells. The final, non-attaching fraction was plated onto YPD. From plates representing a separate initial population of mutagenized cells, colonies were selected and retested to confirm the loss of attachment capability as described above. Then, candidate isolates were purified by a single cell isolation technique and successively cultured for at least five times to evaluate the stability of non-attaching phenotype.

\section{Determination of Biological Characteristics of Wild-Type and Non-attaching Mutant}

Wild-type and mutant of $R$. glutinis were cultured with YPD medium with or without $2 \%$ agar, biological characteristics of colony, cell morphology and growth curve were determined according to methods described elsewhere. In the assay of growth curve, the initial cell concentration of each yeast strains was $1 \times 10^{5}$ cells $/ \mathrm{mL}$, the wavelength for determining OD value of cell cultures was $600 \mathrm{~nm}$.

Surface staining patterns and EPS capsule of wild-type and mutant of $R$. glutinis were assayed with the India ink positive and negative staining methods reported by Buck and Andrews (1999a,b). For inducing formation of EPS capsule, yeast carbon base medium (YCB, Difco) with 3\% glucose was used.

\section{Effects of Wild-Type and Non-attaching Mutant on Spore Germination of B. cinerea In Vitro}

The yeast cells and spores of $B$. cinerea were collected as described above. Yeast cells and spores of $B$. cinerea were mixed and resuspended in sterile $10 \%$ apple juice at final concentrations of $5 \times 10^{7}$ cells $/ \mathrm{mL}$ and $2.5 \times 10^{6}$ spores $/ \mathrm{mL}$, respectively. Aliquot of $100 \mu \mathrm{L}$ water agar (2\%) was added on the center of a sterile glass slide. After $5 \mathrm{~min}, 25 \mu \mathrm{L}$ of the mixture of yeast cells and $B$. cinerea spores was spread on water agar. Suspension containing only $B$. cinerea spores was used as the control. Then, each glass slide was placed in a $9-\mathrm{cm}$ petri dish with a moist filter paper at the bottom. Petri dishes were incubated at $22^{\circ} \mathrm{C}$ for $10 \mathrm{~h}$ after which germination rate of $B$. cinerea spores was examined. Each treatment contained four replications, and at least 200 spores were examined in each replication.

\section{Effects of Wild-Type and Non-attaching Mutant on Mycelial Growth of $B$. cinerea In Vitro}

Yeast cells and spores of $B$. cinerea were mixed and resuspended with sterile distilled water at final concentrations of $5 \times 10^{7}$ cells $/ \mathrm{mL}$ and $2.5 \times 10^{6}$ spores $/ \mathrm{mL}$, respectively. Agar disks (5 $\mathrm{mm}$ diameter) were cut and removed from PDA plates (5 $\mathrm{cm}$ diameter). After vortex for $30 \mathrm{~s}$, aliquot of $25 \mu \mathrm{L}$ of the mixture was added into each well on the PDA plates. PDA plates inoculated $25 \mu \mathrm{L}$ spore suspension of $B$. cinerea were used as the control. The plates were cultured at $22^{\circ} \mathrm{C}$ for $60 \mathrm{~h}$ after 

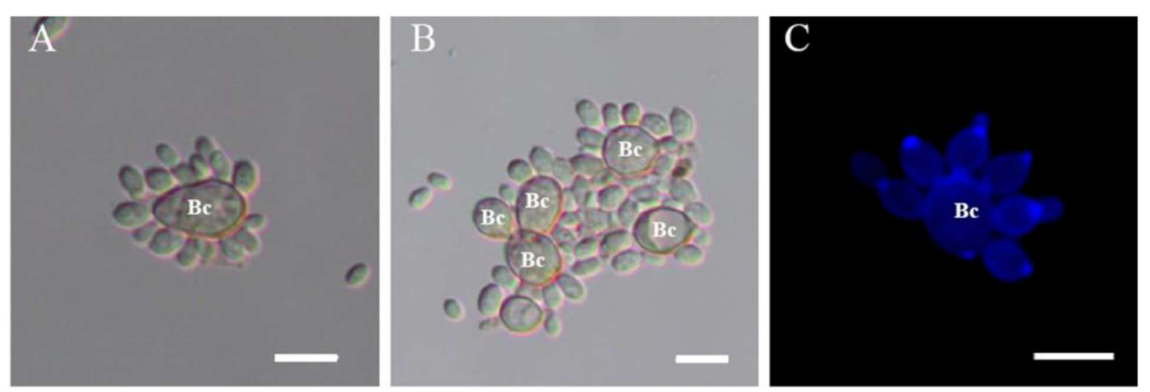

FIGURE 1 | Attachment assay of Rhodotorula glutinis to spores of Botrytis cinerea. (A,B) Attachment between R. glutinis and spores of B. cinerea was observed under light field; (C) Yeast cells mostly attached to spores by the poles of cells, nearby the budding sites which were stained by fluorescent dye calcofluor white. Bc indicates spores of $B$. cinerea. Bar $=10 \mu \mathrm{m}$.
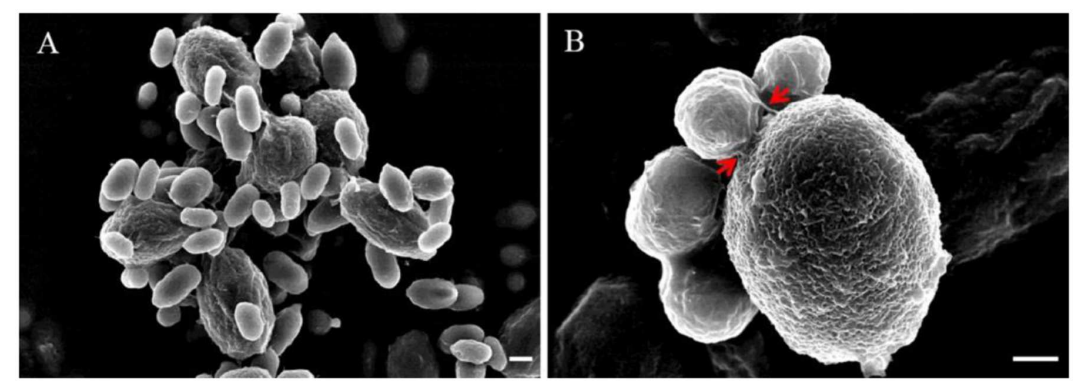

FIGURE 2 | Attachment of R. glutinis and spores of B. cinerea using scanning electron microscopy (SEM). (A), Attachment between R. glutinis and spores of $B$. cinerea was observed under SEM; (B), Close-up view showing the attachment between $R$. g/utinis and $B$. cinerea. Red arrows indicate fibers linking yeast cell and spore of $B$. cinerea. Bar $=1 \mu \mathrm{m}$.

which colony diameter (extension of colony minus the PDA well diameter of $5 \mathrm{~mm}$ ) was measured. Each treatment contained four replications.

\section{Biocontrol Assays}

Four wounds (uniform $4 \mathrm{~mm}$ deep $\times 3 \mathrm{~mm}$ wide) were made on the cheek of each apple fruit with a sterile nail. Wild-type and CE4 strain of $R$. glutinis were collected after culturing for $24 \mathrm{~h}$, resuspended to $1 \times 10^{8}$ cells $/ \mathrm{mL}$ after washing three times using sterile distilled water. The suspension of yeast cells was mixed with equal volume of $B$. cinerea spore suspension of $2 \times 10^{5}$ spores/mL. Then, aliquots of $10 \mu \mathrm{L}$ mixture were inoculated to the wound of apple fruit, respectively. Fruit inoculated with $10 \mu \mathrm{L}$ spore suspension of $B$. cinerea at $1 \times 10^{5}$ spores $/ \mathrm{mL}$ were used as the control. Treated fruit were put in $400 \times 300 \times 100 \mathrm{~mm}$ plastic box, which was covered with a high density polyethylene bag to keep high humidity and stored at $22^{\circ} \mathrm{C}$. Disease incidence and lesion diameter were determined each day until 5 days. Each treatment contained three replicates of eight fruits.

\section{Data Analysis}

Statistical analyses were performed with SPSS version 11.5 (SPSS Inc., Chicago, IL, USA) and analyzed by one-way analysis of variance (ANOVA). Mean separations were performed by Duncan's multiple range tests. Differences at $P \leq 0.05$ were considered significant.

\section{RESULTS}

\section{Attachment between R. glutinis and B. cinerea}

When yeast cells of $R$. glutinis and spores of $B$. cinerea were mixed together, transient and strong attachment between them was observed (Figure 1). Spores of B. cinerea were tightly surrounded by yeast cells (Figure 1A), and a number of spores and yeast cells aggregated together sometimes (Figure 1B). Interestingly, yeast cells mostly attached to spores by the poles of cells, nearby the budding sites (Figure 1C). SEM observation suggested that fibers on the cell surface might play important role in the attachment between yeast cells and spores of B. cinerea (Figure 2). The attachment was also observed between yeast cells of $R$. glutinis and mycelia of $B$. cinerea or other fungal pathogens, such as Monilinia fructicola (data not shown).

\section{Effects of CSE on Attachment between $R$. glutinis and $B$. cinerea}

The attachment capability of $R$. glutinis was vibration-sensitive. The yeast nearly completely lost attachment capability to spores of $B$. cinerea when yeast cells were pre-treated with vibration for $20 \mathrm{~min}$ (data not shown). The result suggested that certain components on the cell surface played critical role during the interaction between $R$. glutinis and $B$. cinerea and exfoliated 
A

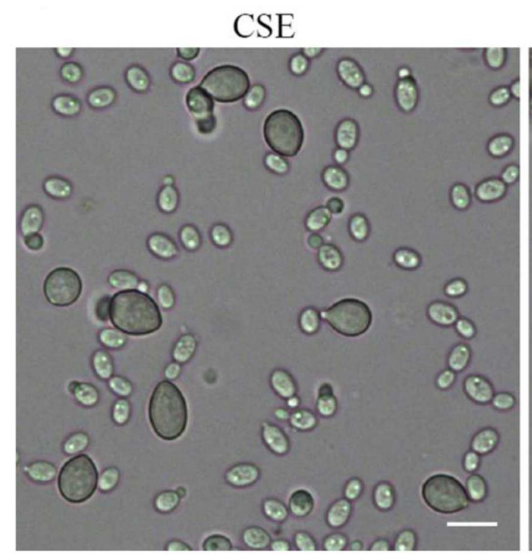

B

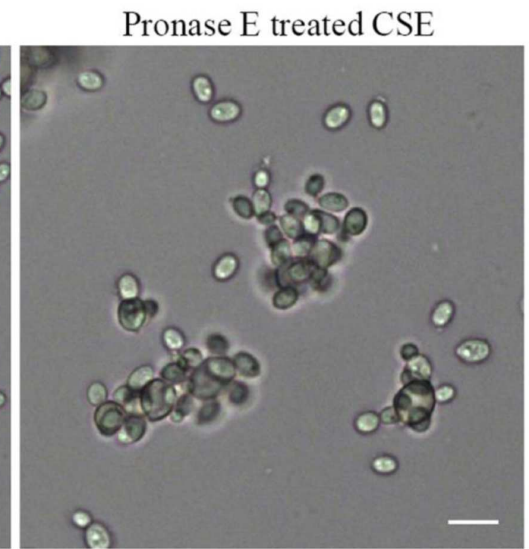

FIGURE 3 | Effects of cell surface extract (CSE) of $\boldsymbol{R}$. glutinis on attachment between yeast cells and spores of $\boldsymbol{B}$. cinerea. Firstly, spores of $B$. cinerea were incubated with CSE (A) or Pronase E treated CSE (B), then attachment between yeast cells and spores of $B$. cinerea was examined. Bar $=10 \mu \mathrm{m}$.

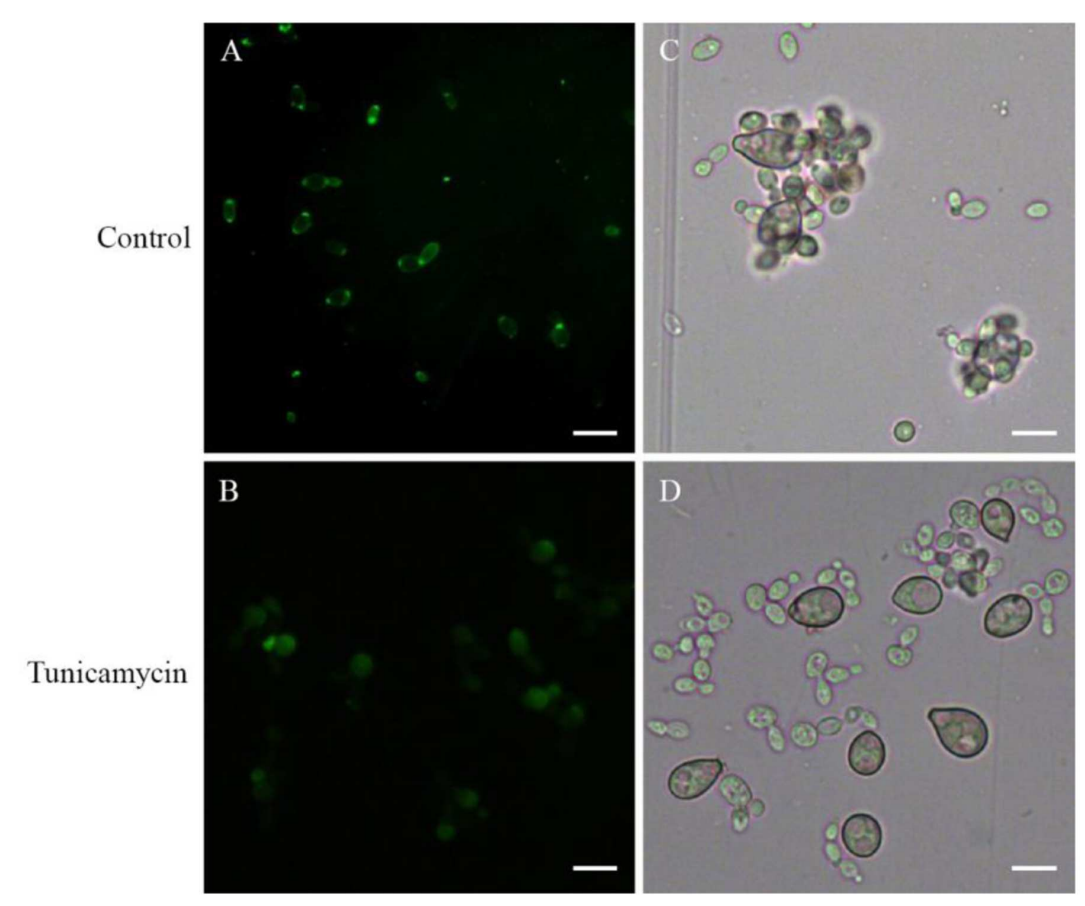

FIGURE 4 | Effects of tunicamycin on attachment between $\boldsymbol{R}$. glutinis and B. cinerea. (A,B) FITC-Con A staining of yeast cells treated or un-treated with $5 \mu \mathrm{g} / \mathrm{mL}$ tunicamycin. (C,D) Attachment assay of yeast cells treated or un-treated with tunicamycin. Bar $=10 \mu \mathrm{m}$.

from cells during vibration. Incubating spores of $B$. cinerea with CSE markedly inhibited the attachment between $R$. glutinis and B. cinerea (Figure 3A). While, the influence of CSE was impaired after it was digested using Pronase E (Figure 3B).

\section{Effects of Tunicamycin on Attachment between $R$. glutinis and $B$. cinerea}

Con $\mathrm{A}$ as a lectin can bind specifically to $\alpha$-Mannose or $\alpha$-Galactose structures in glycoproteins. So the FITC-ConA fluorescence staining could be used to detect the distribution of glycoproteins on cell surface of $R$. glutinis. FITC-Con A fluorescence occurred over the entire cell surface and was very intense at the poles of cells (Figure 4A). The strong polar FITCCon A staining pattern was not observed when $R$. glutinis grew in YPD containing $5 \mu \mathrm{g} / \mathrm{mL}$ tunicamycin (Figure 4B). Further, the tunicamycin treated yeast cells lost attachment capability to spores of $B$. cinerea (Figures $4 \mathbf{C}, \mathbf{D}$ ). It was also found that tunicamycin treated yeast cells reproduced slowly and presented abnormal cell shape. 


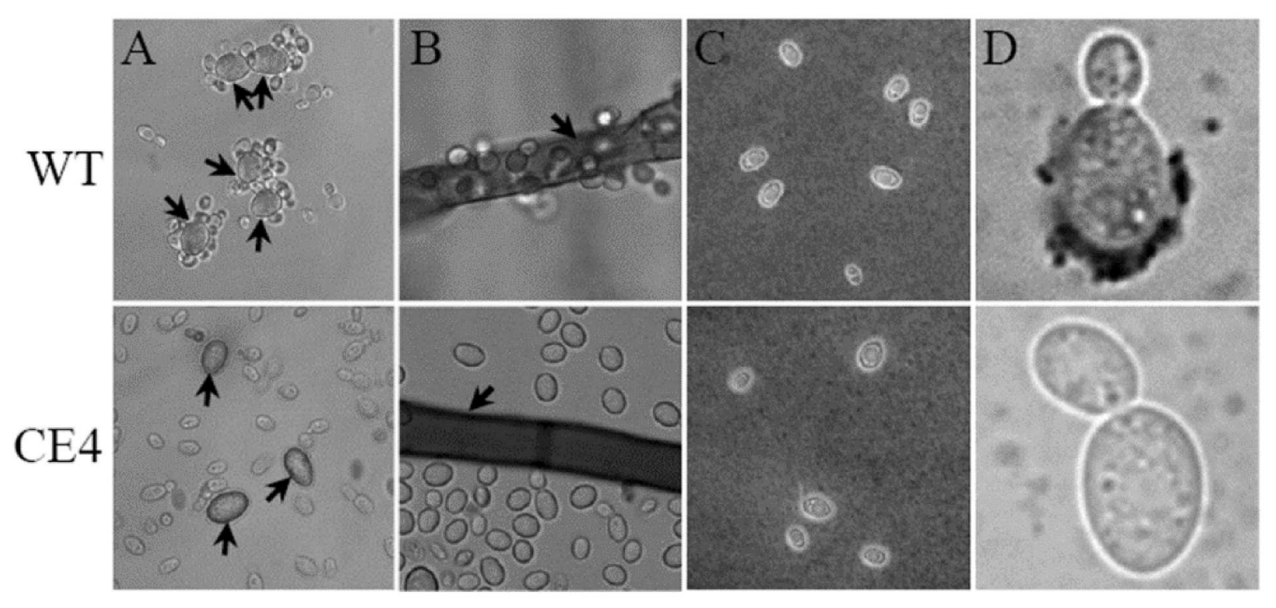

E

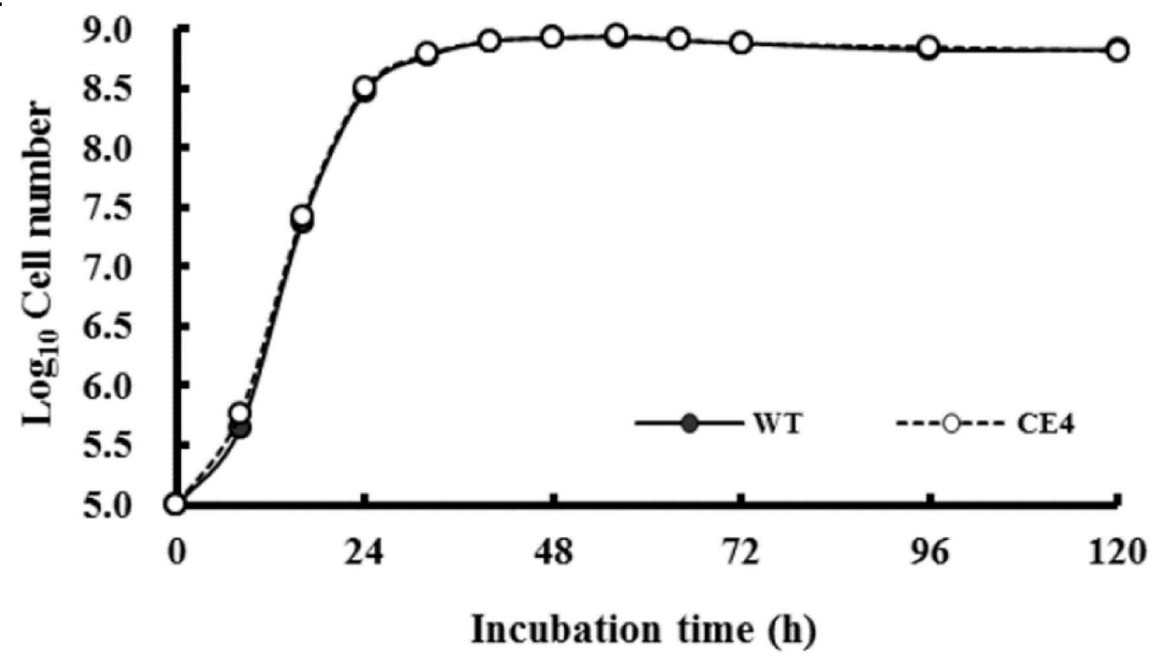

FIGURE 5 | Attachment assay and determination of biological characteristics of $R$. glutinis wild-type (WT) and non-attaching mutant (CE4). (A) attachment assay between $R$. glutinis and spores of B. cinerea (arrows indicating spores of B. cinerea); (B) Attachment assay between $R$. glutinis and hyphae of B. cinerea (arrows indicating hyphae of B. cinerea); (C) India ink staining positive patterns; (D) India ink staining negative patterns; (E) Growth curves of WT and CE4 strains.

\section{Isolation and Characterization of Non-attaching Mutants}

By mutagenizing with EMS, seven non-attaching mutants were obtained from independent initial mutagenized populations. Among them, three mutants were isolated from Fraction A, one mutant from Fraction B and two mutants from Fraction C. However, there was only one mutant (CE4, from Fraction C) showed stable non-attaching phenotype to $B$. cinerea after purification and successive culture (Figures 5A,B). Subsequently, we compared the difference in colony, cell morphology, and reproductive ability between CE4 and wild-type strains cultured in YPD medium. No significant difference in colony appearance and color, cell shape and size were observed. Both CE4 and wildtype strains possessed the capability of EPS capsule formation when cultured in YCB medium and negatively stained with India ink (Figure 5C). However, in the assay of India ink positive staining, a distinct difference between the two strains was found, i.e., India ink could stain the poles of wild-type cells, rather than CE4 cells (Figure 5D). In addition, growth curve of the two strains nearly completely overlapped, indicating the two strains has similar reproductive ability (Figure 5E).

\section{Effects of Wild-Type and Non-attaching Mutant on Spore Germination and Mycelial Growth of B. cinerea}

After $10 \mathrm{~h}$, germination rate of $B$. cinerea spores reached to nearly $100 \%$ in control treatment (Figure 6A). Co-culture of yeast cells and $B$. cinerea spores significantly inhibited spore germination. The germination rate of $B$. cinerea spores in WT treatment was about half of that in CE4 treatment (17 vs. 35\%). Co-culture of wild-type yeast cells and $B$. cinerea also inhibited colony extension (Figure 6B). In contrast, CE4 strain had no significant effect on mycelial growth of $B$. cinerea. 


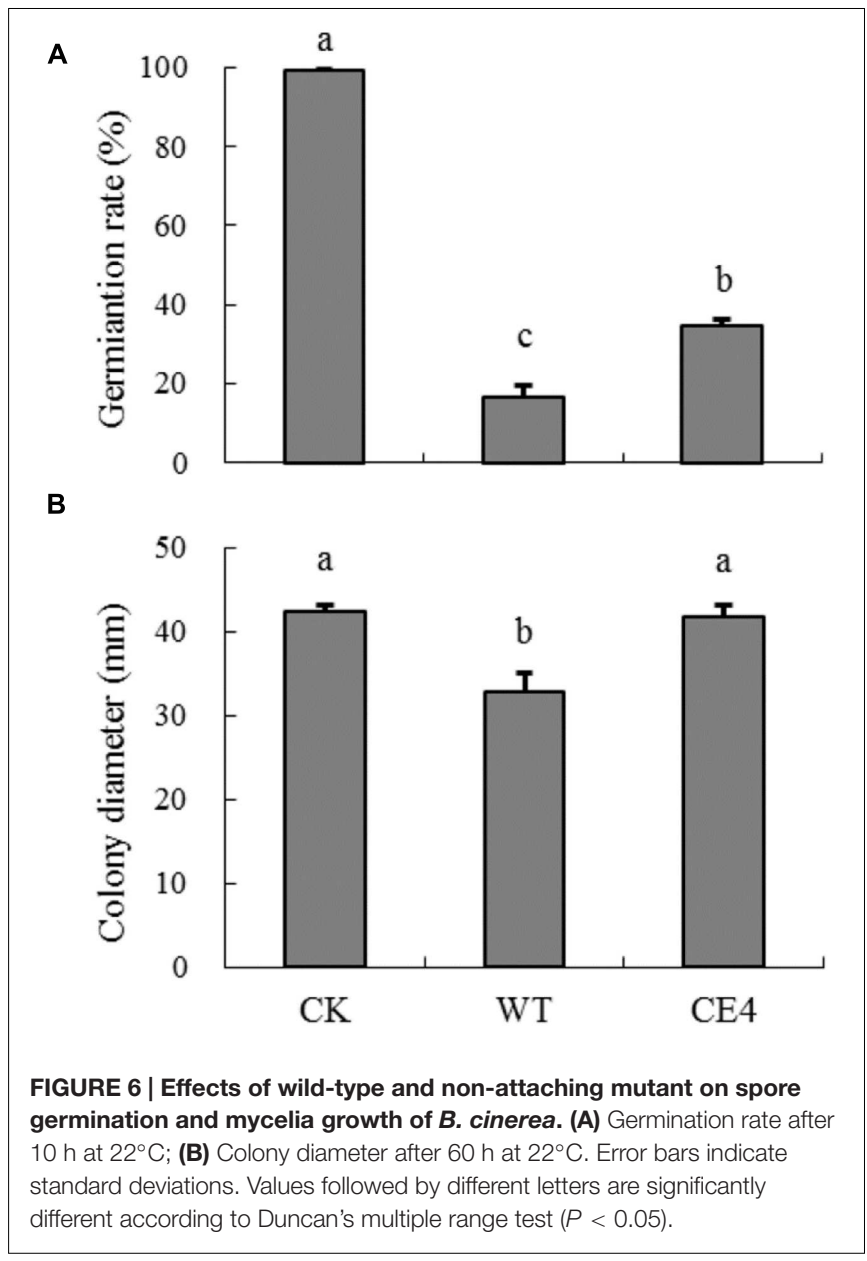

\section{Biocontrol Efficacy of Wild-Type and Non-attaching Mutant}

After stored 5 days at $22^{\circ} \mathrm{C}$, disease incidence of gray mold cause by $B$. cinerea reached $100 \%$ in control fruit, and the average lesion diameter was $23.4 \mathrm{~mm}$ (Figure 7). Inoculation of both wildtype and CE4 strains reduced the disease incidence and lesion diameter in apple fruit. However, fruit treated with wild-type strain showed significantly lower disease incidence ( $75 \%$ vs. $95 \%$ ) and smaller lesion diameter (11.4 $\mathrm{mm}$ vs. $17.8 \mathrm{~mm})$ as compared with CE4 treatment $(P<0.05)$, indicating wild-type provided better control effect than CE4 strain.

\section{DISCUSSION}

Rhodotorula glutinis is a common inhabitant of phylloplane communities (Di Menna, 1959). The yeast has been reported to possess positive attachment capability to post-harvest fungal pathogens, which was considered as one of main biocontrol mechanisms of the biocontrol agent (Castoria et al., 1997; Allen et al., 2004). However, various modes of action may simultaneously involve in the interaction between antagonisms and pathogens. Thus, it is difficult to evaluate the contribution of each action mode possessed by the antagonistic yeast. Isolating
A

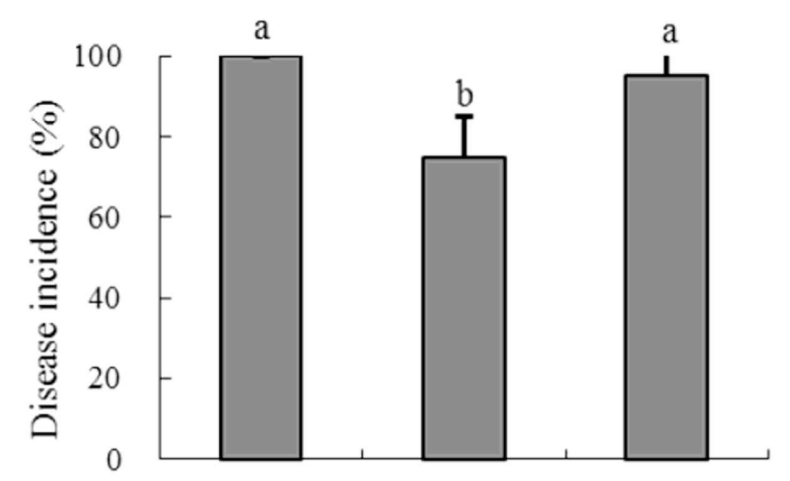

B

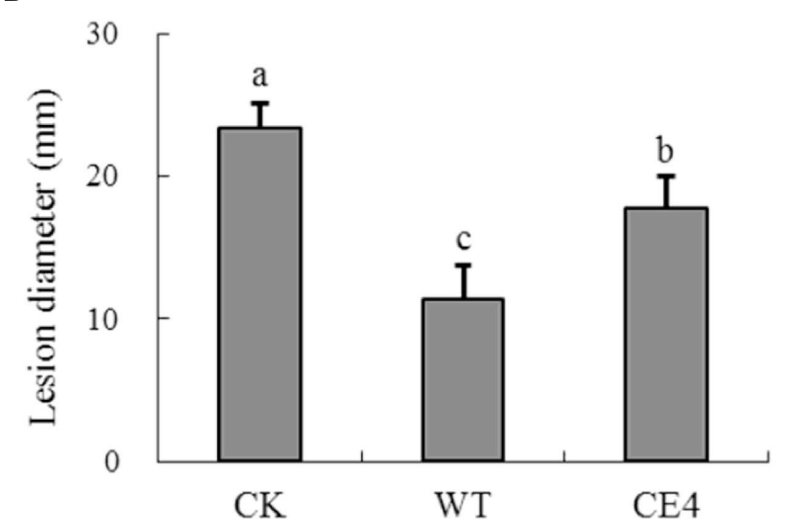

FIGURE 7 | Biocontrol efficacy of R. glutinis wild-type (WT) and non-attaching mutant CE4 against $B$. cinerea in apple fruit. (A) Disease incidence; (B) Lesion diameter. Error bars indicate standard deviations. Values followed by different letters are significantly different according to Duncan's multiple range test $(P<0.05)$.

non-attachment mutants should be a good method to study the importance of attachment.

Rhodotorula glutinis is haploid and suitable for mutagenesis (Tully, 1985). In the present study, we mutagenized R. glutinis wild-type strain by EMS. The method was also used by Buck and Andrews (1999a) on a strain of basidiomycetous yeast Rhodosporidium toruloides (anamorph, $R$. glutinis). During the processes of screening non-attaching mutants, we used mycelia of $B$. cinerea to exclude attached yeast cells instead of polystyrene petri dishes. Because cells of wild-type can tenaciously attach to B. cinerea mycelia, the modification let us obtain non-attaching mutants more efficiently. The method may provide help for isolating non-attaching mutants in other yeast species. With the method, we obtained a mutant, CE4, which completely lost the attachment capability (Figures 5A,B). In addition, no significant differences in colony color, cell shape, and cell size were observed between CE4 and wild-type. Moreover, the two strains showed equal reproductive ability (Figure 5E). Reproductive ability of biocontrol agents is closely related with successful colonization in fruit wounds and important for biocontrol (Janisiewicz and Korsten, 2002). Interestingly, wild-type strain of $R$. glutinis 
showed better performance on inhibiting spore germination and mycelial growth of $B$. cinerea than CE4 strain when yeast cells were co-cultured with $B$. cinerea in vitro (Figure 6). Further, biocontrol efficacy of CE4 strain was significantly lower than that of wild-type strain, though CE4 strain also reduced the disease incidence and lesion diameter against gray mold caused by $B$. cinerea in apple fruit (Figure 7 ). These results suggested that the attachment of $R$. glutinis to $B$. cinerea contributed to the full biocontrol efficacy, and other modes of action were also involved. Competition for nutrition and space might be still the main mode of action for $R$. glutinis to control post-harvest diseases. In the biocontrol assay, wild-type strain showed about $25 \%$ efficacy of disease incidence after 5 days by comparing with control, which was relatively lower than that reported in previous studies (Zhang et al., 2009; Yan et al., 2014). The results might be caused by the lower ratio of yeast cells relative to $B$. cinerea spores $\left(5 \times 10^{7}\right.$ cells $/ \mathrm{mL}$ vs. $1 \times 10^{5}$ spores $/ \mathrm{mL}$ ) in the present study. In addition, simultaneous inoculation of yeast cells and $B$. cinerea spores might also lead higher disease incidence than inoculation of yeast cells ahead of pathogen.

Important role of extracellular polymeric substances (EPS) in cell attachment has been well documented in Candida species (Seneviratne et al., 2008). For antagonistic yeasts, Andrews et al. (1994) reported that formation of EPS capsule contributed to attachment of Aureobasidium pullulans. Whereas, our results showed that both wild-type and non-attaching mutant CE4 could produce capsules by analysis of India ink negative staining (Figure 5C), indicating that produce of EPS capsule is not the prerequisite to cell attachment for yeasts. Similar result was also reported by Buck and Andrews (1999a).

Interestingly, we observed that yeast cells mostly attached to spores of $B$. cinerea by the poles of cells (Figure 1). At the same time, both FITC-Con A and India ink positive staining showed a strong polar pattern in the wild-type strain of R. glutinis (Figures $\mathbf{4 A}$ and 5D), suggesting that certain components on cell poles might play an important role in the attachment. As attachment capability of $R$. glutinis was vibration-sensitive, the critical components might loosely bind to the cell surface. The components could be included in CSE by vibration treatment, and blocked the attachment sites on the surface of $B$. cinerea spores during incubation, finally inhibited the attachment between $R$. glutinis and B. cinerea

\section{REFERENCES}

Allen, T. W., Burpee, L. L., and Buck, J. W. (2004). In vitro attachment of phylloplane yeasts to Botrytis cinerea, Rhizoctonia solani, and Sclerotinia homoeocarpa. Can. J. Microbiol. 50, 1041-1048. doi: 10.1111/j.1744-7348.1997.tb05152.x

Andrews, J. H., Harris, R. F., Spear, R. N., Lau, G. W., and Nordheim, E. V. (1994). Morphogenesis and adhesion of Aureobasidium pullulans. Can. J. Microbiol. 40, 6-17. doi: 10.1139/m94-002

Banani, H., Spadaro, D., Zhang, D., Matic, S., Garibaldi, A., and Gullino, M. L. (2014). Biocontrol activity of an alkaline serine protease from Aureobasidium pullulans expressed in Pichia pastoris against four post-harvest pathogens on apple. Int. J. Food Microbiol. 18, 1-8. doi: 10.1016/j.ijfoodmicro.2014. 05.001
(Figure 3A). On the contrary, CSE treated by Pronase E could not inhibit the attachment (Figure 3B), indicating some proteins were involved in the attachment. These proteins might be glycosylated, because tunicamycin, an inhibitor of $N$-glycoprotein synthesis, impaired the attachment capability of R. glutinis (Figure 4D). Critical roles of cell surface proteins, especially glycoproteins in adhesion interaction have been reported in previous studies (Teixeira et al., 2014; de Oliveira et al., 2015).

\section{CONCLUSION}

A non-attaching mutant of the biocontrol yeast strain, $R$. glutinis CE4, was generated by a modified method of EMS mutagenesis. This mutant exhibited weaker ability on inhibiting spore germination and mycelial growth of $B$. cinerea in vitro, as well as lower biocontrol effect against $B$. cinerea in apple fruit, compared to the wild-type strain. These results suggested that attachment capability of $R$. glutinis to $B$. cinerea contributed to its biocontrol efficacy. Furthermore, certain protein components, which loosely bound to the cell surface and mainly located on cell poles, might play a critical role in the attachment between $R$. glutinis and B. cinerea. The components and involved molecular mechanisms are worth investigating in future study, which will provide help to enhance efficacy of biocontrol agents.

\section{AUTHOR CONTRIBUTIONS}

ST conceived and designed the experiments. BL and HP performed the experiments. BL analyzed the data. BL and ST drafted the manuscript. All authors read and approved the final manuscript.

\section{ACKNOWLEDGMENTS}

This work was supported by the Ministry of Science and Technology of China (Grant No. 2015BAD16B01-3), the Key Research Program of Chinese Academy of Sciences (Grant No. KFZD-SW-102) and Youth Innovation Promotion Association CAS (2015063).

Buck, J. W., and Andrews, J. H. (1999a). Attachment of the yeast Rhodosporidium toruloides is mediated by adhesives localized at sites of bud cell development. Appl. Environ. Microbiol. 65, 465-471.

Buck, J. W., and Andrews, J. H. (1999b). Localized, positive charge mediates adhesion of Rhodosporidium toruloides to barley leaves and polystyrene. Appl. Environ. Microbiol. 65, 2179-2183.

Castoria, R., De-Curtis, F., Lima, G., and De-Cicco, V. (1997). 及-1,3-glucanase activity of two saprophytic yeasts and possible mode of action as biocontrol agents against post-harvest diseases. Postharvest Biol. Technol. 12, 293-300. doi: 10.1016/S0925-5214(97)00061-6

Chan, Z. L., and Tian, S. P. (2005). Interaction of antagonistic yeasts against post-harvest pathogens of apple fruit and possible mode of action. Postharvest Biol. Technol. 36, 215-223. doi: 10.1016/j.postharvbio.2005. 01.001 
Chen, J., Li, B., Qin, G., and Tian, S. (2015). Mechanism of $\mathrm{H}_{2} \mathrm{O}_{2}$-induced oxidative stress regulating viability and biocontrol ability of Rhodotorula glutinis. Int. J. Food Microbiol. 193, 152-158. doi: 10.1016/j.ijfoodmicro.2014.10.025

de Oliveira, H. C., Assato, P. A., Marcos, C. M., Scorzoni, L., de Paula, E., Silva, A. C., et al. (2015). Paracoccidioides-host interaction: an overview on recent advances in the paracoccidioidomycosis. Front. Microbiol. 6:1319. doi: $10.3389 /$ fmicb. 2015.01319

Di Menna, M. E. (1959). Yeasts from the leaves of pasture plants. N. Z. J. Agric. Res. 2, 394-405. doi: 10.1080/00288233.1959.10420328

Droby, S., Wisniewski, M., Macarisin, D., and Wilson, C. (2009). Twenty years of post-harvest biocontrol research: is it time for a new paradigm? Postharvest Biol. Technol. 52, 137-145. doi: 10.1016/j.postharvbio.2008.11.009

El-Ghaouth, A., Wilson, C. L., and Wisniewski, M. (1998). Ultrastructural and cytochemical aspects of the biological control of Botrytis cinerea by Candida saitoana in apple fruit. Phytopathology 88, 282-291. doi: 10.1094/PHYTO.1998.88.4.282

Ge, L., Zhang, H., Chen, K., Ma, L., and Xu, Z. (2010). Effect of chitin on the antagonistic activity of Rhodotorula glutinis against Botrytis cinerea in strawberries and the possible mechanisms involved. Food Chem. 120, 490-495. doi: 10.1016/j.foodchem.2009.10.042

Janisiewicz, W. J., and Korsten, L. (2002). Biological control of postharvest diseases of fruits. Annu. Rev. Phytopathol. 40, 411-441. doi: 10.1146/annurev.phyto.40.120401.130158

Lahlali, R., Hamadi, Y., Drider, R., Misson, C., El Guilli, M., and Jijakli, M. H. (2014). Control of citrus blue mold by the antagonist yeast Pichia guilliermondii Z1: compatibility with commercial fruit waxes and putative mechanisms of action. Food Control 45, 8-15. doi: 10.1016/j.foodcont.2014.04.014

Li, B., Wang, W., Zong, Y., Qin, G., and Tian, S. (2012). Exploring pathogenic mechanisms of Botrytis cinerea secretome under different ambient $\mathrm{pH}$ based on comparative proteomic analysis. J. Proteome Res. 11, 4249-4260. doi: $10.1021 / \mathrm{pr} 300365 \mathrm{f}$

Liu, J., Sui, Y., Wisniewski, M., Droby, S., and Liu, Y. (2013). Review: utilization of antagonistic yeasts to manage post-harvest fungal diseases of fruit. Int. J. Food Microbiol. 167, 153-160. doi: 10.1016/j.ijfoodmicro.2013.09.004

Qin, G. Z., Tian, S. P., Liu, H. B., and Xu, Y. (2003). Biocontrol efficacy of three antagonistic yeasts against Penicillium expansum in harvested apple fruits. Acta Bot. Sin. 45, 417-421.

Seneviratne, C. J., Jin, L., and Samaranayake, L. P. (2008). Biofilm lifestyle of Candida: a mini review. Oral Dis. 14, 582-590. doi: 10.1111/j.16010825.2007.01424.x

Sharma, R. R., Singh, D., and Singh, R. (2009). Biological control of post-harvest diseases of fruits and vegetables by microbial antagonists: a review. Biol. Control 50, 205-221. doi: 10.1016/j.biocontrol.2009.05.001

Soylu, E. M., Kurt, S., and Soylu, S. (2010). In vitro and in vivo antifungal activities of the essential oils of various plants against tomato grey mould disease agent Botrytis cinerea. Int. J. Food Microbiol. 143, 183-189. doi: 10.1016/j.ijfoodmicro.2010.08.015

Spadaro, D., and Droby, S. (2016). Development of biocontrol products for post-harvest diseases of fruit: the importance of elucidating the mechanisms of action of yeast antagonists. Trends Food Sci. Technol. 47, 39-49. doi: 10.1016/j.tifs.2015.11.003

Spadaro, D., and Gullino, M. L. (2004). State of the art and future prospects of the biological control of post-harvest fruit diseases. Int. J. Food Microbiol. 91, 185-194. doi: 10.1016/S0168-1605(03)00380-5

Teixeira, P. A., Penha, L. L., Mendonça-Previato, L., and Previato, J. O. (2014). Mannoprotein MP84 mediates the adhesion of Cryptococcus neoformans to epithelial lung cells. Front. Cell Infect. Microbiol. 4:106. doi: $10.3389 /$ fcimb. 2014.00106

Tully, M. (1985). Enrichment of mutants of Rhodosporidium toruloides by the use of inositol starvation. J. Basic Microbiol. 25, 683-686. doi: 10.1002/jobm.3620251020

Weiberg, A., Wang, M., Lin, F. M., Zhao, H. W., Zhang, Z. H., Kaloshian, I., et al. (2013). Fungal small RNAs suppress plant immunity by hijacking host RNA interference pathways. Science 342, 118-123. doi: 10.1126/science.1239705

Williamson, B., Tudzynsk, B., Tudzynski, P., and van Kan, J. A. L. (2007). Botrytis cinerea: the cause of grey mould disease. Mol. Plant Pathol. 8, 561-580. doi: 10.1111/j.1364-3703.2007.00417.x

Wisniewski, M., Biles, C., Droby, S., McLaughlin, R., Wilson, C., and Chalutz, E. (1991). Mode of action of the post-harvest biocontrol yeast, Pichia guilliermondii. I. characterization of attachment to Botrytis cinerea. Physiol. Mol. Plant Pathol. 39, 245-258. doi: 10.1016/0885-5765(91)90033-E

Wisniewski, M., Wilson, C., Droby, S., Chalutz, E., El-Ghaouth, A., and Stevens, C. (2007). "Post-Harvest biocontrol: new concepts and applications," in Biological Control: a Global Perspective, eds C. Vincent, M. S. Goettal, and G. Lazarovits (Cambridge: CABI), 262-273.

Yan, F., Xu, S., Chen, Y., and Zheng, X. (2014). Effect of rhamnolipids on Rhodotorula glutinis biocontrol of Alternaria alternata infection in cherry tomato fruit. Postharvest Biol. Technol. 97, 32-35. doi: 10.1016/j.postharvbio.2014.05.017

Yao, H., Tian, S., and Wang, Y. (2004). Sodium bicarbonate enhances biocontrol efficacy of yeasts on fungal spoilage of pears. Int. J. Food Microbiol. 93, 297-304. doi: 10.1016/j.ijfoodmicro.2003.11.011

Yu, C., Zhou, T., Sheng, K., Zeng, L., Ye, C., Yu, T., et al. (2013). Effect of pyrimethanil on Cryptococcus laurentii, Rhodosporidium paludigenum, and Rhodotorula glutinis biocontrol of Penicillium expansum infection in pear fruit. Int. J. Food Microbiol. 164, 155-160. doi: 10.1016/j.ijfoodmicro.2013.04.012

Yu, T., Li, H. Y., and Zheng, X. D. (2007). Synergistic effect of chitosan and Cryptococcus laurentii on inhibition of Penicillium expansum infections. Int. J. Food Microbiol. 114, 261-266. doi: 10.1016/j.ijfoodmicro.2006.09.008

Zhang, D., Spadaro, D., Garibaldi, A., and Gullino, M. L. (2011). Potential biocontrol activity of a strain of Pichia guilliermondii against grey mold of apples and its possible modes of action. Biol. Control 57, 193-201. doi: 10.1016/j.biocontrol.2011.02.011

Zhang, H., Ma, L., Turner, M., Xu, H., Zheng, X., Dong, Y., et al. (2010). Salicylic acid enhances biocontrol efficacy of Rhodotorula glutinis against post-harvest Rhizopus rot of strawberries and the possible mechanisms involved. Food Chem. 122, 577-583. doi: 10.1016/j.foodchem.2010.03.013

Zhang, H., Wang, L., Ma, L., Dong, Y., Jiang, S., Xu, B., et al. (2009). Biocontrol of major post-harvest pathogens on apple using Rhodotorula glutinis and its effects on post-harvest quality parameters. Biol. Control 48, 79-83. doi: 10.1016/j.biocontrol.2008.09.004

Conflict of Interest Statement: The authors declare that the research was conducted in the absence of any commercial or financial relationships that could be construed as a potential conflict of interest.

Copyright (C) 2016 Li, Peng and Tian. This is an open-access article distributed under the terms of the Creative Commons Attribution License (CC BY). The use, distribution or reproduction in other forums is permitted, provided the original author(s) or licensor are credited and that the original publication in this journal is cited, in accordance with accepted academic practice. No use, distribution or reproduction is permitted which does not comply with these terms. 